\title{
Efficient Synthesis of B-Alkylated Oxazaborolidines Derived from Ephedrine and Norephedrine
}

\author{
Margarita Ortiz-Marciales ${ }^{*}$, Eduvigis González, Melvin De Jesús, Sandraliz Espinosa, Wildeliz \\ Correa, Johanna Martínez, and Ruth Figueroa \\ Department of Chemistry, University of Puerto Rico-Humacao, CUH Station, Humacao, Puerto Rico \\ 00791, USA
}

\begin{abstract}

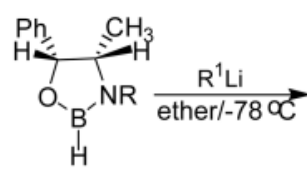

$\mathrm{R}=\mathrm{H}, \mathrm{Me}$ norephedrine were prepared in good yield and excellent purity by one pot treatment of $B-\mathrm{H}$ oxazaborolidines with the corresponding organolithium reagent, and subsequent hydrolysis of the cyclic borohydride intermediate with anhydrous ammonium chloride.
\end{abstract}

Chiral 1,3,2-oxazaborolidines have been well studied and regarded as important catalysts for the enantioselective reduction of prochiral ketones, imines and oximes, ${ }^{1,2,3}$ and in other stereoselective transformations. ${ }^{4}$ The development of oxazaborolidines has been limited mainly by the availability of suitable chiral amino alcohols. Norephedrine and ephedrine are commercially available and relatively inexpensive in their two enantiomeric forms.

Consequently, their derived oxazaborolidines, and particularly the $B$-alkyl substituted systems, have been widely investigated and reported as highly efficient chiral templates for the borane reduction of prochiral ketones ${ }^{5}$ and $\mathrm{C}=\mathrm{N}$ double bonds, ${ }^{6}$ in catalytic hydroboration, ${ }^{7}$ as well as in addition of diethylzinc to aldehydes. ${ }^{8}$

$B$-H oxazaborolidines are usually prepared by the reaction of norephedrine or ephedrine with borane-THF or borane dimethylsulfide complex. ${ }^{4 \mathrm{c}}$ Their extreme sensitivity to air and moisture make these reagents difficult to purify by distillation or recrystallization, and therefore, they are commonly prepared in situ for subsequent reactions. ${ }^{9}$ However, side products present with the unpurified $B$-H heterocyclic catalysts or reagents cause a detrimental effect on the enantiomeric purity of desired chiral products. ${ }^{10}$ Furthermore, when $B$-H oxazaborolidines are left over a period of time can form dimers or oligomers that alter the nature of the chiral catalyst. $4 \mathrm{~d}, 11$ On the contrary, $B$-alkylated compounds are more stable, easier to purify and handle than the nonsubstituted counterparts, and produce similar enantioselectivities. ${ }^{5 \mathrm{e}} B$-substituted 1,3,2oxazaborolidines are typically prepared by condensation of the amino alcohols with boronic acids,5a boroxines, $5 \mathrm{~d}, 5 \mathrm{e}$ or their boronate esters, $4 \mathrm{c}$ removing water and boronic acid, or boronic ester residues, by azeotropic distillation in toluene. ${ }^{5 \mathrm{~d}}$ The treatment of chiral amino

m_ortiz@cuhac.upr.clu.edu.

Supporting Information Available. Spectroscopic data from $B$-alkylated oxazaborolidines. This material is free of charge via Internet at http://pubs.acs.org. 
alcohols with organo-bis(diisopropylamino)borane for the synthesis of $B$-alkyl and phenyl oxazaborolidines has also been reported. ${ }^{12}$ However, these methods require expensive and elaborated reagents, and moreover, the complete removal of water is extremely difficult.

Herein, we describe a novel approach for one pot synthesis of pure $B$-alkyl-1,3,2oxazaborolidines derived from ephedrine and norephedrine via alkylation of the parent boraheterocyclic compound $\mathbf{1}$, as indicated in scheme $1 .{ }^{13}$

In our previous work, ${ }^{14}$ we observed an unprecedented $B$-alkylation of the oxazaborolidine 1 derived from (1R, 2S)-(-)-norephedrine by the n-butyllithium addition, forming the corresponding cyclic borohydride $\mathbf{2}$, as illustrated in scheme 2 . After an aqueous work-up, the boronic acid derivative $\mathbf{3 b}$ was isolated in $91 \%$ crude yield, as clear oil, and identified by ${ }^{11} \mathrm{~B},{ }^{1} \mathrm{H},{ }^{13} \mathrm{C}$ NMR and IR spectral data. ${ }^{15}$ Intermediate $\mathbf{3 b}$ was observed to be stable to acid and base hydrolysis and can be potentially valuable as a suitable source for the heterocyclic catalyst $\mathbf{4 b}$. Contrary to the butylboronic acid condensation procedure to prepare $\mathbf{4 b}$, used by Garcia and coworkers, ${ }^{5 \mathrm{~d}}$ the formation of this compound was successfully completed by heating $3 \mathbf{b}$, obtaining a $75 \%$ yield of the distilled product with more than $95 \%$ purity by GC/ MS, ${ }^{1} \mathrm{H}$ and ${ }^{13} \mathrm{C}$ NMR. ${ }^{16}$

The approach given in scheme 2 was then investigated for the synthesis of other common $B$ alkyl 1,3,2-oxazaborolidines derived from (1R, 2S)(-)-norephedrine and (1R, 2S)-(-)ephedrine. Initially, the $B$-H oxazaborolidines were synthesized by a modification of the established condensation reaction of the corresponding chiral 1,2-amino alcohol with boraneTHF, ${ }^{4 c, d}$ and characterized by ${ }^{11} \mathrm{~B}$ and ${ }^{13} \mathrm{C}$ NMR spectroscopy. ${ }^{4 \mathrm{~d}, 17}$ The boron alkylation with $n$-butyl-, or methyllithium, of the in situ prepared $B$-H oxazaborolidine took place readily at $-78{ }^{\circ} \mathrm{C}$, forming the lithium borohydride salt 2 . Upon treatment with an aqueous ammonium chloride solution, extraction with ether or dichloromethane, and drying the organic phase with sodium sulphate, produced the crude boronic acid intermediate 3 with good purity (> 85\% by GC/MS) and excellent yield, as illustrated in Table 1.

In the case of analogues $\mathbf{3 a}, \mathbf{c}$ and $\mathbf{d}$, the yields of the pure $B$-alkyl-oxazaborolidines obtained by the previous dehydration method were modest because the boronic acid intermediate $\mathbf{3}$ codistilled with the oxazaborolidine. The yields of the desired heterocyclic products were only slightly improved by azeotropic distillation of the water using toluene or xylene and $4 \AA$ molecular sieves. ${ }^{5 \mathrm{~d}}$ In addition, other side products were observed by GC/MS.

After attempting to find a better alternative to prepare the $B$-alkylated oxazaborolidine from the borohydride intermediate 2 by treatment with MeI or TMSCl, the use of anhydrous ammonium chloride provided the expected oxazaborolidines in good yield and with excellent purity as indicated by GC/MS, ${ }^{11} \mathrm{~B},{ }^{1} \mathrm{H}$ and ${ }^{13} \mathrm{C}$ NMR. ${ }^{16}$ The boiling points and ${ }^{11} \mathrm{~B}$ NMR signals of $B$-methyl and n-butyl substituted oxazaborolidines 4 , and the isolated yields of the analytical pure compounds prepared by the aqueous and dry methods, are shown in table 2 .

\section{Typical experimental procedure}

To a solution of Borane-THF ( $43 \mathrm{mmol}, 43 \mathrm{~mL}, 1.0 \mathrm{M}$ ) at room temperature was added dropwise a solution of $(1 \mathrm{R}, 2 \mathrm{~S})(-)$ norephedrine $(2.5 \mathrm{~g}, 15.5 \mathrm{mmol})$ in THF $(25 \mathrm{~mL})$. After the clear reaction mixture was stirred for $12 \mathrm{hr}$ at room temperature, the solvents were removed under vacuum $(20 \mathrm{mmHg})$ and the white foamy residue was gradually heated in an oil bath to $130^{\circ}$ $\mathrm{C}$ and maintained at this temperature for $30 \mathrm{~min}$. A clear crystalline solid compound was obtained, which by ${ }^{11} \mathrm{~B},{ }^{1} \mathrm{H}$ and ${ }^{13} \mathrm{C}$ NMR was similar to the $B$ - $\mathrm{H}-1,3,2$-oxazaborolidine reported by Quallich. ${ }^{17}$ A solution of $\mathrm{n}-\mathrm{BuLi}(18.6 \mathrm{mmol}, 8.0 \mathrm{~mL}, 2.32 \mathrm{M}$ in hexanes) was added in $15 \mathrm{~min}$ to the previous obtained solid dissolved in anhydrous ether $(30 \mathrm{~mL})$ and cooled at $-78^{\circ} \mathrm{C}$. The mixture was stirred overnight at $25^{\circ} \mathrm{C}$. The pale rose mixture with a fine 
suspension was cooled at $0^{\circ} \mathrm{C}$ and then allowed to react with solid ammonium chloride $(4.4 \mathrm{~g}$, $82.5 \mathrm{mmol}$ ) for $4 \mathrm{~h}$ at room temperature. The solid was removed by filtration using a Schlenk filter under nitrogen flow and vacuum $(15 \mathrm{mmHg})$. The filtrated was concentrated using a vacuum pump and heated at $40^{\circ} \mathrm{C}$ obtaining the crude product ( $3.9 \mathrm{~g}, 99 \%$ yield). A short path distillation at reduced pressure furnished the pure $\boldsymbol{B}$-butyl-1,3,2-oxazaborolidine $\mathbf{4 b}$ as a clear oil $(2.0 \mathrm{~g}, 56 \%, 98 \%$ purity by GC/MS $)$; Bp $82{ }^{\circ} \mathrm{C} / 0.1 \mathrm{mmHg}$; IR $\left(v \mathrm{~cm}^{-1}\right) 3219(\mathrm{NH}) ;{ }^{11} \mathrm{~B}$ NMR (500 MHz), $\delta\left(\mathrm{CDCl}_{3}, \mathrm{ppm}\right) 35 ;{ }^{1} \mathrm{H} \delta 7.3(\mathrm{~m}, 5 \mathrm{H}), 7.50(\mathrm{~d}, J=6 \mathrm{~Hz}, 1 \mathrm{H}), 3.9(\mathrm{~m}, 1 \mathrm{H})$, 3.5 (br. s, $1 \mathrm{H}, \mathrm{NH}), 1.5(\mathrm{~m}, 4 \mathrm{H}), 0.9(\mathrm{~m}, 5 \mathrm{H}), 0.6(\mathrm{~d}, J=6 \mathrm{~Hz}, 3 \mathrm{H}) ;{ }^{13} \mathrm{C} \delta 139.6,127.7,127.2$, 126.7, 126.1, 82.1, 53.8, 27.3, 25.4, 20.4, 13.8, 11.3 (br.); MS (m/z): $216.9\left(\mathrm{M}^{+}\right.$), 202 (100\%).

In summary, we have achieved the first efficient and direct approach to $B$-alkylated oxazaborolidines derived from ephedrine and norephedrine via alkylation of the $B-\mathrm{H}$ precursors, opening a new avenue for the preparation of other important $B$-substituted oxazaborolidines, which are presently under study.

\section{Supplementary Material}

Refer to Web version on PubMed Central for supplementary material.

\section{Acknowledgments}

Financial support by the National Institute of Health through their MBRS (GM 08216) and NIH-AREA (GM 59829) grants is greatly appreciated. The NIH-MARC, DOD-ONR and NSF-AMP undergraduate's support is also gratefully acknowledged. From the University of Puerto Rico, Río Piedras, we thank Professor John A. Soderquist for his helpful discussions and Mr. José Martínez for obtaining the NMR spectra.

\section{References}

1. Hirao A, Itsuno S, Nakahama S, Yamazaki Y. J Chem Soc, Chem Commun 1981:315-317.

2. (a) Corey EJ, Helal CJ. Angew Chem Int Ed 1998;37:1986-2012. (b) Deloux L, Srebnik M. Chem Rev 1993;93:763-784. (c) Singh VK. Synthesis 1992:605-617. (d) Wallbaum S, Martens J. Tetrahedron: Asymm 1992;3:1475-1504.

3. (a) Nakagawa M, Kawate T, Kakikawa T, Yamada H, Matsui T, Hino T. Tetrahedron 1993;49:17391748. (b) Fontaine E, Namane C, Meneyrol J, Geslin M, Serva L, Roussey E, Tissandie S, Maftouh M, Roger P. Tetrahedron: Asymm 2001;12:2185-2189. (c) Puigjaner C, Vidal-Ferran A, Moyano A, Pericas MA, Riera A. J Org Chem 1999;64:7902-7911.

4. (a) Seerden J-PG, Boeren MMM, Scheeren HW. Tetrahedron 1997;53:11843-11852. (b) Corey EJ, Cimprich KA. J Am Chem Soc 1994;116:3151-3152. (c) Joshi NN, Srebnik M, Brown HC. Tetrahedron Lett 1989;30:5551-5554. (d) Brown JM, Lloyd-Jones GC. Tetrahedron: Asymm 1990;1:869-872.

5. (a) Caze C, El-Moualij N, Hodge P, Lock CJ, Ma J. J Chem Soc, Perkin Trans 1 1995:345-349. (b) Cho BT, Chun YS. Tetrahedron Asymm 1992;3:1539-1542. (c) Berenguer R, Garcia J, Vilarrasa J. Tetrahedron: Assymm 1994;5:165-168. (d) Bach J, Berenguer R, Jordi Garcia J, Loscertales T, Vilarrasa J. J Org Chem 1996;61:9021-9025. [PubMed: 11667889] (e) Quallich, GJ.; Blake, JF.; Woodall, TM. Diphenyloxazaborolidines for Enantioselective Reduction of Ketones. In: AbdelMagid, AF., editor. Reductions in Organic Synthesis. Vol. Chapter 7. American Chemical Society; Washington, DC: 1996. p. 112-126. (f) Quallich GJB, James F, Woodall Teresa M. J Amer Chem Soc 1994;116:8516-8525.

6. (a) Cho TB, Ryu MH. Bull Korean Chem Soc 1994;15:191-192. (b) Cho BT, Ryu MH, Chun YS, Dauelsberg C, Wallbaum S, Martens J. Bull Korean Chem Soc 1994;15:53-57. (c) Dougherty JT, Flisak JR, Hayes J, Lantos I, Liu L, Tucker L. Tetrahedron Asymmetry 1997;8:497-500.

7. Brown JM, Lloyd-Jones GC. J Chem Soc, Chem Commun 1992:710-713.

8. Cho BT, Chun YS. Bull Korean Chem Soc 1996;17:1096-1098.

9. Sakito Y, Yoneyoshi Y, Suzukamo G. Tetrahedron Lett 1988;29:223-224. 
10. Mathre DJ, Thompson AS, Douglas AW, Hoogsteen K, Carroll JD, Corley EG, Grabowski EJJ. J Org Chem 1993;58:2880-2888.

11. (a) Brown JM, Lloyd-Jones GC, Layzell TP. Tetrahedron: Asymm 1993;4:2151-2154. (b) Nevalainen V. Tetrahedron Asymm 1994;5:387-394.

12. Chavant PY, Vaultier M. J Organometallic Chem 1993;455:37-46.

13. Ortiz-Marciales, M.; De Jesús, M.; González, E.; Espinosa, S.; Correa, W. US Patent Application. 60/445, 743. Feb. 2003

14. Ortiz-Marciales, M.; González, E.; Figueroa, R.; Martínez, J.; Muñoz, X.; Espinosa, S.; Correa, W. Presentation 820, Abstracts of Papers, 223rd National Meeting of the American Chemical Society; Orlando, Fl. Washington, DC: American Chemical Society; 2002. CHED

15. (a) $\mathrm{NMR}$ in $\mathrm{CDCl}_{3}(\delta \mathrm{ppm}):{ }^{11} \mathrm{~B} 9.2 ;{ }^{1} \mathrm{H} 7.3-6.9(\mathrm{~m}, \mathrm{Ph}) ; 4.9(\mathrm{~d}, \mathrm{~J}=5.2, \mathrm{PhCH}-\mathrm{O}) ; 4.4$ (s, br, OH); 3.4 (m, CH-N); 3.0 (s, br, $\left.\mathrm{NH}_{2}\right) ; 1.2-1.1\left(\mathrm{~m}, \mathrm{CH}_{2}\right) ; 0.87-0.79\left(\mathrm{~m}, \mathrm{CH}_{2}, \mathrm{CH}_{3}\right) ; 0.67$ (d, J = 5.3, $\left.\mathrm{CH}_{3}\right) ;{ }^{13} \mathrm{C} 140.9\left(\mathrm{C}_{\text {para }}\right), 128-126,77.4(\mathrm{PhCH}-\mathrm{O}), 53.1(\mathrm{CH}-\mathrm{N}), 27.2,26.7,20.6,14.3$; IR ( $v$ $\mathrm{cm}^{-1}$ ): 3352 (br, OH, $\left.\mathrm{NH}_{2}\right) 1603$ (br, NH $\mathrm{NH}_{2}$ ). GC/MS (70ev, m/z) $217\left(\mathrm{M}^{+} \cdot-\mathrm{H}_{2} \mathrm{O}\right), 202$ (100\%). (b) This compound is new, however no analytical sample could be obtained due to its partial dehydration on purification. (c) B-phenyl boronic acid intermediates formed by the addition of water to oxazaborolidines were reported by Rico AR, Tlahuextl M, Flores-Parra A, Contreras R. J Organomet Chem 1999;581:122-128.

16. See supporting information.

17. Quallich, GJ. US Patent. 6,037505. May 14. 2000 


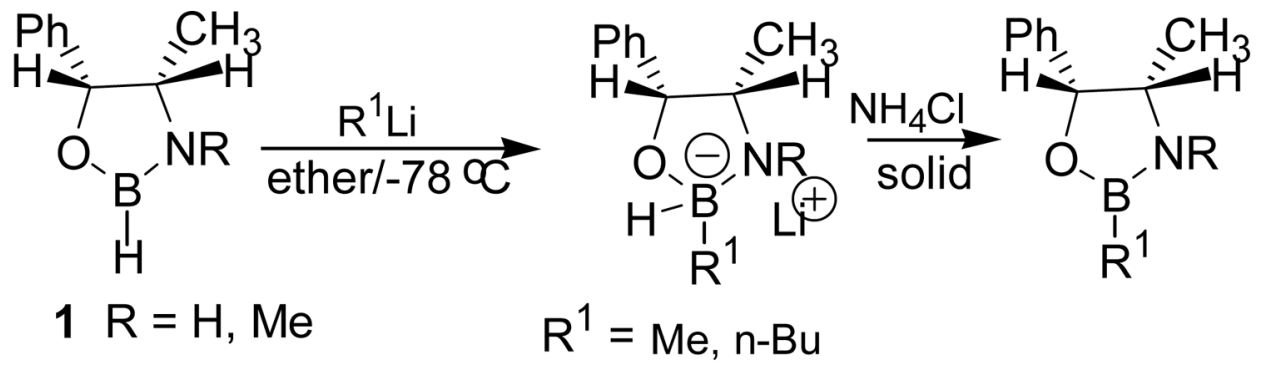

Scheme 1. 


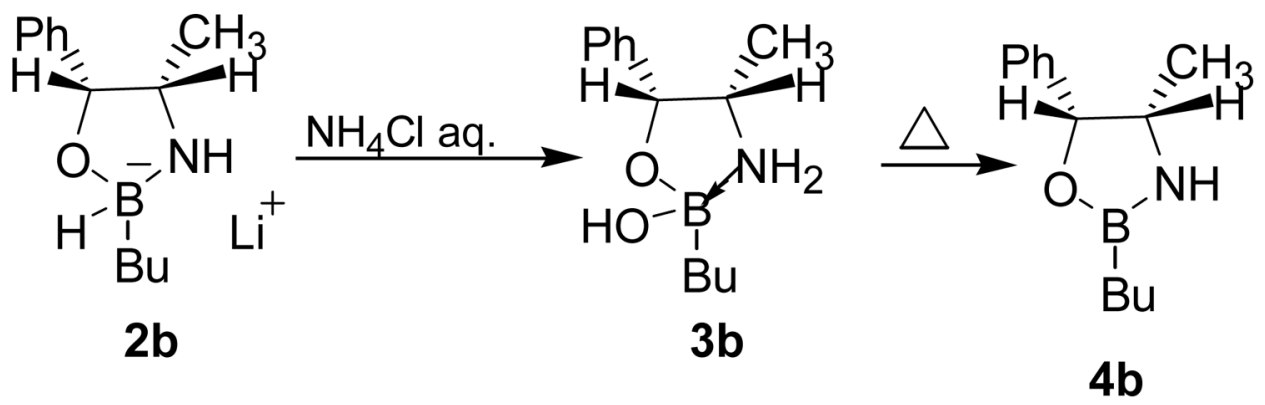

Scheme 2. 
Table 1

Boronic Acid Derivatives Prepared by Alkylation of the $\boldsymbol{B}$-H Oxazaborolidine $\mathbf{1}$



Org Lett. Author manuscript; available in PMC 2010 January 25. 


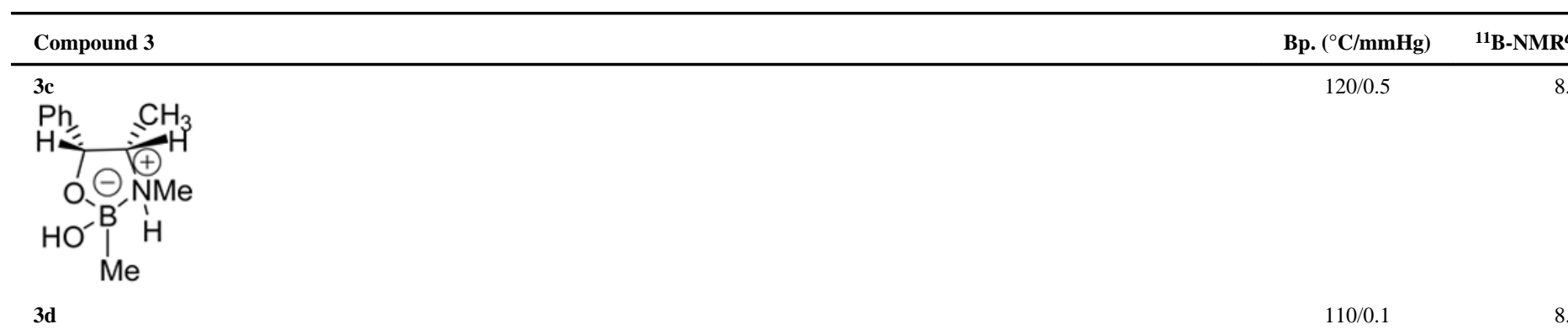

\section{(1)}


1

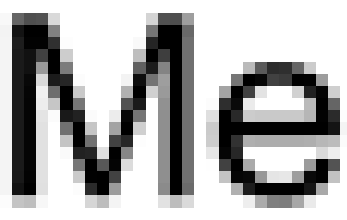

4.
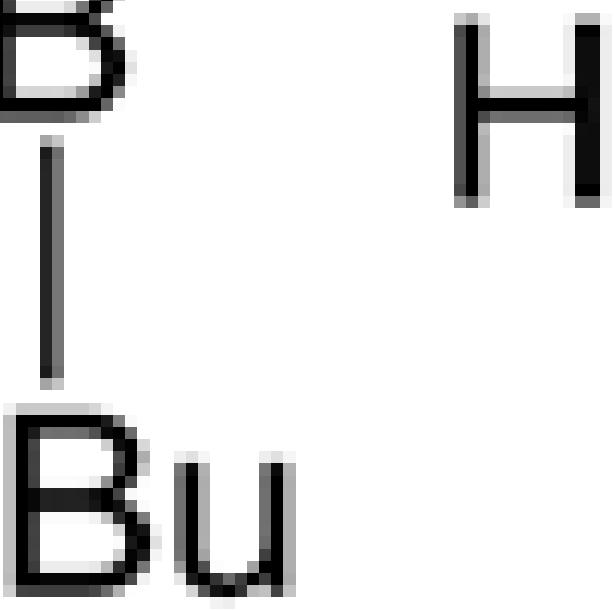

${ }^{a}$ Chemical displacements using $\mathrm{BF}_{3}-\mathrm{OEt}_{2}$ as internal standard.

Org Lett. Author manuscript; available in PMC 2010 January 25. 
${ }^{b}$ Yield of crude product based on the corresponding amino alcohol.

${ }^{c}$ Pure compounds were not obtained due to partial dehydration during distillation. 


\section{Table 2}

$B$-Alkyl Oxazaborolidines Prepared by $B$ Alkylation of the Parent Heterocyclic Compound

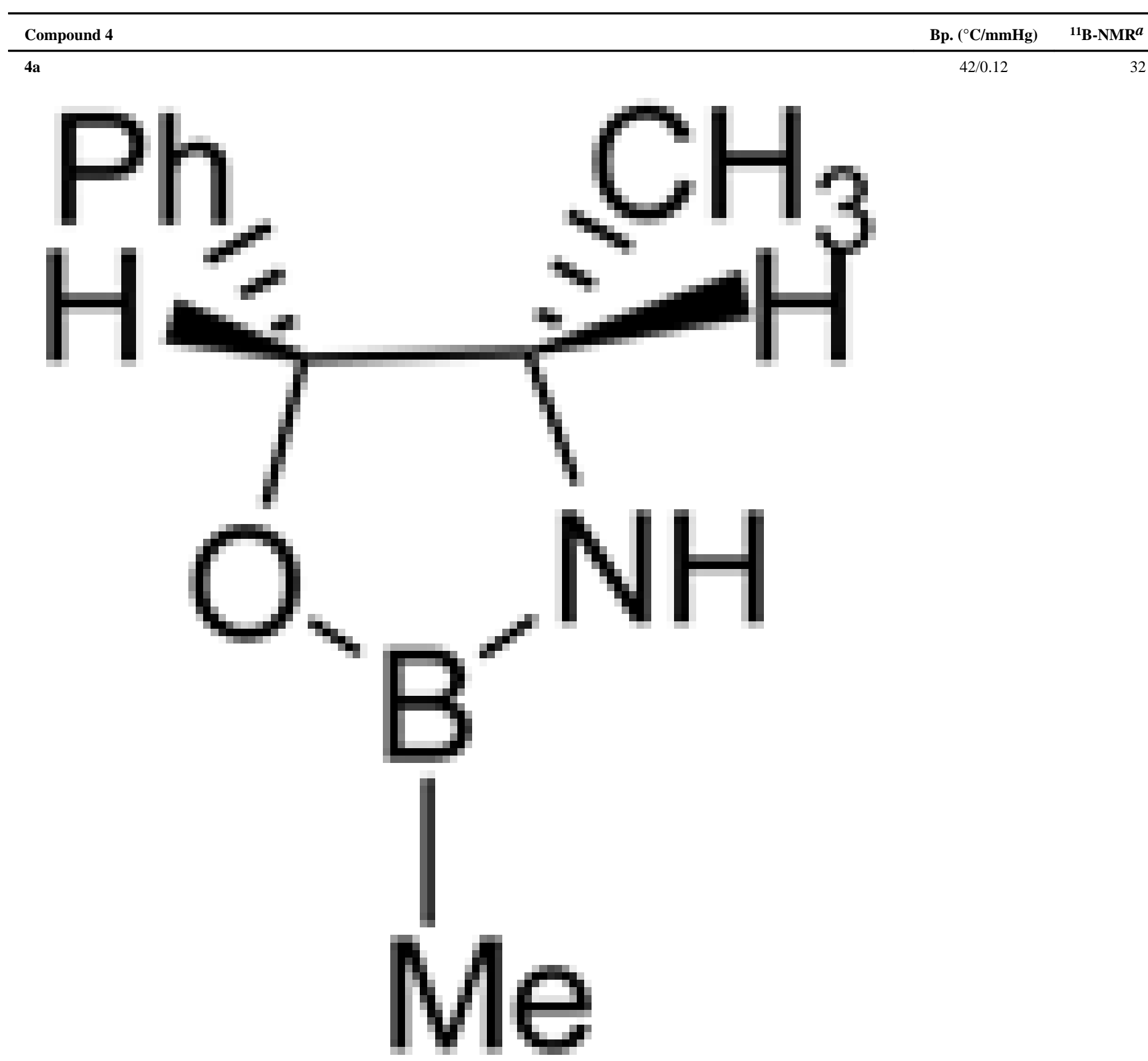

Org Lett. Author manuscript; available in PMC 2010 January 25. 


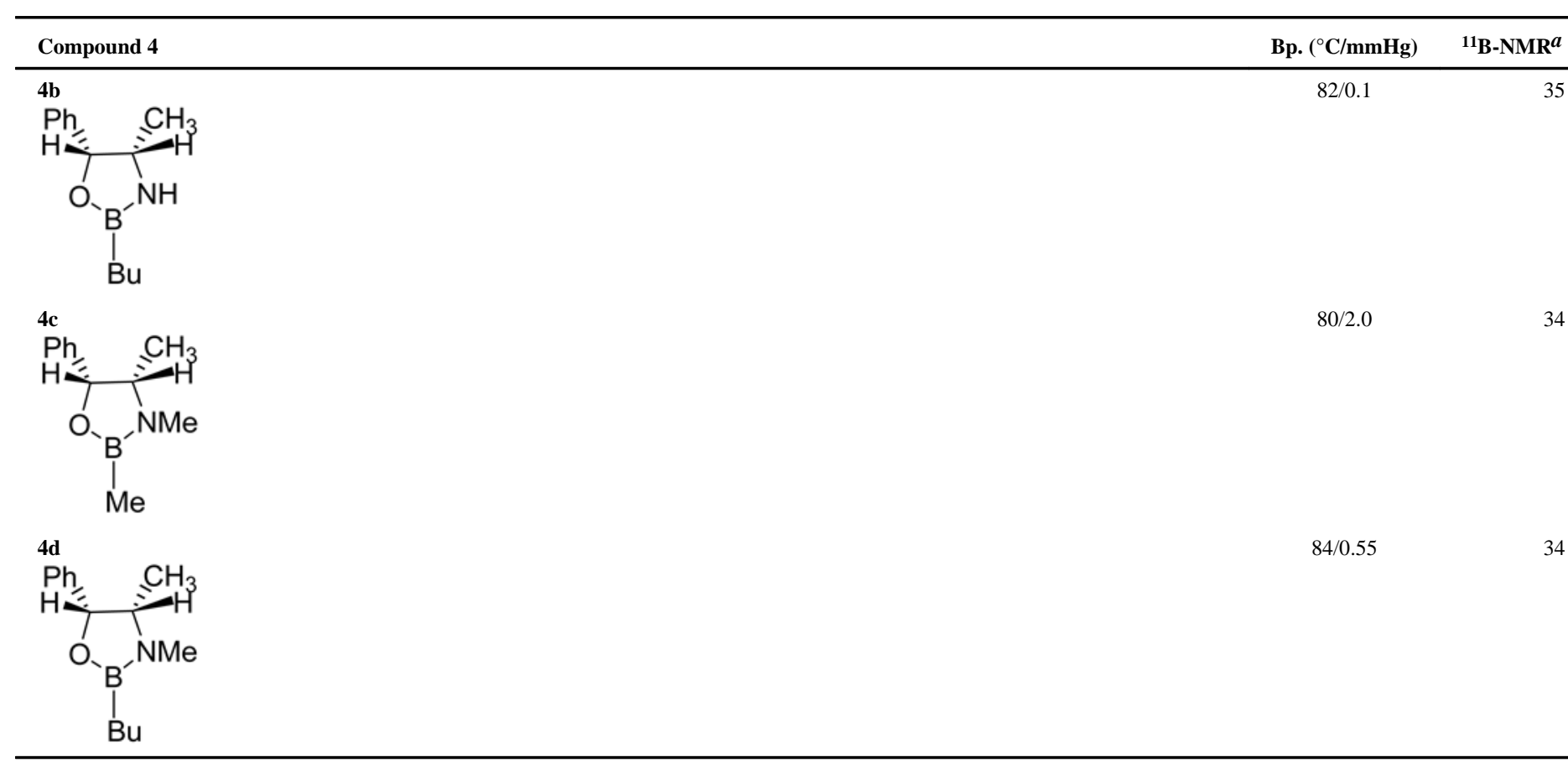

${ }^{a}$ Chemical displacements using BF3-OEt2 as internal standard.

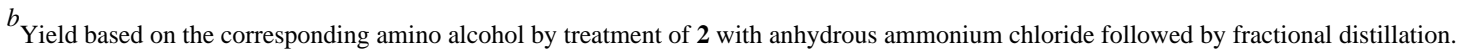

${ }^{c}$ By treatment of $\mathbf{2}$ with aqueous ammonium chloride and calculated from crude product $\mathbf{3}$. 